\title{
Submerged fermentation of laccase producing Streptomyces chartreusis using box-behnken experimental design
}

\author{
Ronak Chhaya ${ }^{1}$, H.A.Modi ${ }^{2}$ \\ ${ }^{1}$ Department of Life Sciences, School of Sciences, Gujarat University, Ahmedabad, 380009, Gujarat, India \\ ${ }^{2}$ Department of Life Sciences, School of Sciences, Gujarat University, Ahmedabad, 380009, Gujarat, India
}

\begin{abstract}
Response surface methodology was engaged for the optimization of diverse nutritional and physical parameters for laccase production by Streptomyces chartreusis strain NBRC 12753 in the submerged fermentation process. Screening of production parameters was executed using Plackett-Burman design and the variables with statistically momentous effects on laccase production were recognized. Variables such as Cupric sulphate, Pyrogallol and Yeast extract were selected for further optimization studies using Box-Behnken design. The multiple regression coefficients $\left(R^{2}\right)$ had a value of 0.9606, indicating that the model could explain up to $96.06 \%$ of the variability of the response. This methodology facilitated analysis of the experimental data to establish the optimum conditions for the process and understand the contribution of individual factors to evaluate the response under optimal conditions. Thus application of Box-Behnken approach appears to have potential usage in process application.
\end{abstract}

Key words-Box-behnken, Laccase, Response surface methodology, Submerged fermentation

\section{Introduction}

The use of microorganisms for the production of commercially vital metabolites has increased rapidly over the past half century and the production of enzymes in submerged fermentation $(\mathrm{SmF})$ has long been acknowledged. SmF, more strongly developed from the 1940's onwards because of the necessity to produce antibiotics on a large scale has been characterized as fermentation in the presence of excess water [1]. Almost all the large-scale enzyme producing facilities have been used the established approach of SmF owing to better monitoring and ease of handling [2]. A historic number of highly cost-effective SmF processes are known to exist not only for enzyme production but also for the production of several other metabolites and are being productively exploited by industry in most countries of the world. Wide investigations have accomplished great developments in the technology dominant the earlier shortcomings due to unoptimised preculture and other growth conditions. The production of laccases from different microorganisms by submerged fermentation has been reported [3, 4]. Submerged fermentation is the cultivation of organisms in liquid culture media. This mode of fernentation has many advantages with respect to the purity of the product and easiness in controlling different process parameters and scale-up processes. The optimization of various process parameters by conventional method for laccase production has been reported [5]. A gene for a laccase isoenzyme called lacP83 from Pleorotus ostreatus ATCC32783 was obtained only by submerged fermentation conditions [6]. Laccase production is reported to enhance by Trametes hirusta using Wheat Bran under Submerged Fermentation [7]. Optimization of different nutrients levels for laccase production using $\mathrm{SmF}$ were studied [8]. Submerged liquid culturing is usually preferred for large-scale fermentations [9], and has been used extensively for industrial production of antibiotics, amino acids, ethanol, organic acids, baker's and distiller's yeasts. Submerged fermentation is considered more readily available, economical, and practical than other methods for mass production of biopesticides in developed countries [10, 11, and 12]. Statistical Experimental designs are commanding tools for probing the key factors rapidly from a multivariable system. Plackett - Burman design [13] is most widely used for screening multiple factors at a time. This experimental design is particularly useful for initial screening and optimizing only the main effects. Prior to the optimization of the basal liquid medium, the ability of two selected species strain R1 and strain R2 to grow and produce laccase in the original basal liquid medium was further evaluated [1].

\section{Materials and Methods}

\subsection{Organism}

Screening for laccase-producing microbes on Bennet's agar plates containing coloured indicators resulted in isolation of 20 Streptomyces strains. Bacterial isolates showing positive Bavendamm's reaction were maintained on Bennets agar at $30^{\circ} \mathrm{C}$ and stored at $4^{\circ} \mathrm{C}$. The best Laccase producing isolates was identified by comparing the partial $16 \mathrm{~S}$ ribosomal RNA gene partial sequence deposited in GenBank data base and identified as Streptomyces chartreusis strain NBRC 12753 (Accession number JQ086575)[1]. This isolates is use here for further optimization. 


\subsection{Chemicals}

2, 2-Azino-bis (3ethylbenzthiozoline-6-sulphonic acid) (ABTS) and syringaldazine was purchased from Sigma (St. Louis M.O., U.S.A.). Yeast Malt agar, Casein enzyme hydrolysate, Yeast extract powder, Sodium chloride, Dextrose and Guaiacol were procured from Hi-Media (Mumbai, India). Ortho-anisidine and para-anisidine were procured from CDH (Mumbai, India). Pyrogallol and cupric sulphate were procured from S.D.Fine chem (Mumbai, India). All other chemicals were of analytical grade procured from Qualigens (Mumbai, India).

\subsection{Basel Medium and cultural conditions for submerged fermentation $(\mathrm{SmF})$}

The basal medium used for laccase production had the following composition $(\mathrm{g} / \mathrm{L})$ : Casein enzyme hydrolysate; - 2.0, Yeast Extract;- 3.0, NaCl;- 0.1, Dextrose;-5.0, CaCO3; - 0.02, CuSO4; -0.001, pH -7.5 and 1 $\mathrm{ml}$ of trace elements solution [14]. The trace elements solution contained $0.1 \% \mathrm{FeSO} 4,0.09 \% \mathrm{ZnSO} 4$ and 0.02 $\% \mathrm{MnSO} 4, \mathrm{pH} 7.5$. Adequate aeration was provided by agitation at 7.17 relative centrifugal force (rcf) at $30{ }^{\circ} \mathrm{C}$ for 3 days. The culture grown under the same conditions for $48 \mathrm{~h}$ was used as the inoculum for enzyme production.

\subsection{Statistical Optimization for Laccase Production by physicochemical parameters}

The optimization of physicochemical factors for laccase production was carried out in two stages. First is screening of physicochemical factors using Plackett-Burman design. The Plackett-Burman experimental design is a two-level factorial design, which identifies the critical physicochemical parameters required for elevated enzyme production by screening $N$ variables in $N+1$ experiments [13], but it does not consider the interaction effect among the variables [15]. The variables that are found significant in this initial screening can be further optimized using response surface methodology (RSM). Plackett-Burman experimental design consisting of a set of 12 experiments was used to determine the relative significance of 11 factors that influenced laccase production by Streptomyces chartreusis strain NBRC 12753 in submerged fermentation. The complete experimental design is shown in table 2 . The factors or independent variables considered for study included 5 physical factors (pH, Temperature, Inoculum size, Substrate weight and Time course, respectively) and 6 nutritional factors (Dextrose, Yeast extract, Pyrogallol, o-anisidine, p-anisidine and $\mathrm{CuSO}_{4} \cdot 5 \mathrm{H}_{2} \mathrm{O}$ respectively). 12 components with high and low value were described in table 1 . The effect of each variable was determined by the equation as, $\mathrm{E}(\mathrm{xi})=2\left(\sum \mathrm{Mi}^{+}-\mathrm{Mi}\right) / \mathrm{N}$, Where $\mathrm{E}$ (xi) is the concentration effect of the tested variable $\mathrm{Mi}^{+}$and $\mathrm{Mi}{ }^{-}$are the laccase production from the trial examination where the variable (xi) calculated was estimated by the variance among the dummy variables as, Veff $=\sum\left(\mathrm{Ed}^{2}\right) / \mathrm{n}$, Where Veff is the variance of the concentration effect, Ed is the concentration effect for the dummy variables and $\mathrm{n}$ is the number of dummy variables [16]. The standard error (S.E.) of the concentration effect was the square root of the variance of an effect and the significance level ( $p$ value) of each concentration effect was measured using student's $t$ test, $t(x i)$ $=$ Exi/S.E , Where, Exi is the effect of variable xi. Second is optimization of significant variables using BoxBehnken designesponse surface methodology using Box-Behnken design [17] was adopted to find the optimum levels of the significant variables (Cupric sulphate, Pyrogallol and Yeast Extract) and the effects of their mutual interactions on enzyme production. A total of 17 experiments were carried out. Each independent variable was studied at three different levels (low, medium and high, coded as $-1,0$ and +1 , respectively) [15]. The center point of the design was replicated five times for the estimation of error. The experimental design used for the study is shown in Table 2. The Design-Expert ${ }^{\circledR}$ (Version 7.0.2, Stat-ease Inc., USA) was used for experimental design, data analysis and quadratic model building. Each run was performed in triplicate and the average of laccase yield obtained was taken as the experimental values of the dependent variable or response $(Y)$, while predicted values of the response were obtained from quadratic model fitting techniques. The response surface graphs were obtained to understand the effect of variables individually and in combination, and to determine their optimum levels for maximum laccase production.

TABLE 1. Variables screening medium components used in Plackett-Burman design for SmF

\begin{tabular}{|c|c|c|c|}
\hline Variables & Medium components & + Values (g/l) & - Values (g/l) \\
\hline K1 & Cupric sulphate & 0.2 & 0.02 \\
\hline K2 & Temperature & 40 & 30 \\
\hline K3 & Inoculum size & 12 & 5 \\
\hline K4 & Substrate weight & 5 & 24 \\
\hline K5 & Time Course & 72 & 0.01 \\
\hline K6 & o-anisidine & 0.1 & 0.05 \\
\hline K7 & Pyrogallol & 0.5 & 0.2 \\
\hline K8 & Yeast extract & 2 & 0.2 \\
\hline K9 & Sucrose & 2 & 7 \\
\hline K10 & pH & 8 & \\
\hline
\end{tabular}


Submerged fermentation of laccase producing Streptomyces chartreusis using box-behnken

\begin{tabular}{|c|c|c|c|}
\hline $\mathrm{K} 11$ & Dextrose & 5 & 0.5 \\
\hline $\mathrm{K} 12$ & p-anisidine & 0.1 & 0.01 \\
\hline
\end{tabular}

TABLE 2. Plackett-Burman design matrix of twelve variables (K1-K12) and three dummy variables (D1D3) along with observed response (Laccase production for $\mathrm{SmF}$ )

\begin{tabular}{|c|c|c|c|c|c|c|c|c|c|c|c|c|c|c|c|c|}
\hline $\begin{array}{c}\text { Run } \\
\text { No. }\end{array}$ & $\mathrm{K} 1$ & $\mathrm{~K} 2$ & $\mathrm{~K} 3$ & $\mathrm{~K} 4$ & $\mathrm{~K} 5$ & $\mathrm{~K} 6$ & $\mathrm{~K} 7$ & $\mathrm{~K} 8$ & $\mathrm{~K} 9$ & $\mathrm{~K} 10$ & $\mathrm{~K} 11$ & $\mathrm{~K} 12$ & $\mathrm{D} 1$ & $\mathrm{D} 2$ & $\mathrm{D} 3$ & $\mathrm{U} / \mathrm{gm}$ \\
\hline $\mathrm{X} 1$ & + & - & + & + & - & + & - & + & - & + & - & - & + & - & + & 23.0 \\
\hline $\mathrm{X} 2$ & + & + & - & + & + & - & + & - & + & - & + & - & - & + & - & 231.9 \\
\hline $\mathrm{X} 3$ & - & + & + & - & + & + & - & + & - & + & - & + & - & - & + & 26.38 \\
\hline $\mathrm{X} 4$ & + & - & + & + & - & + & + & - & + & - & + & - & + & - & - & 134 \\
\hline $\mathrm{X} 5$ & - & + & - & + & + & - & + & + & - & + & - & + & - & + & - & 234.7 \\
\hline $\mathrm{X} 6$ & - & - & + & - & + & + & - & + & + & - & + & - & + & - & + & 36.11 \\
\hline $\mathrm{X} 7$ & + & - & - & + & - & + & + & - & + & + & - & + & - & + & - & 87.45 \\
\hline $\mathrm{X} 8$ & - & + & - & - & + & - & + & + & - & + & + & - & + & - & + & 40.0 \\
\hline $\mathrm{X} 9$ & + & - & + & - & - & + & - & + & + & - & + & + & - & + & - & 52.77 \\
\hline $\mathrm{X} 10$ & - & + & - & + & - & - & + & - & + & + & - & + & + & - & + & 23.33 \\
\hline $\mathrm{X} 11$ & + & - & + & - & + & - & - & + & - & + & + & - & + & + & - & 340 \\
\hline $\mathrm{X} 12$ & - & + & - & + & - & + & - & - & + & - & + & + & - & + & + & 48.61 \\
\hline $\mathrm{X} 13$ & + & - & + & - & + & - & + & - & - & + & - & + & + & - & + & 378.4 \\
\hline $\mathrm{X} 14$ & + & + & - & + & - & + & - & + & - & - & + & - & + & + & - & 35.33 \\
\hline $\mathrm{X} 15$ & - & + & + & - & + & - & + & - & + & - & - & + & - & + & + & 45.0 \\
\hline $\mathrm{X} 16$ & - & - & - & - & - & - & - & - & - & - & - & - & - & - & - & 8.0 \\
\hline
\end{tabular}

III. Results And Discussion

3.1 Screening of parameters using Plackett-Burman design

TABLE 3. Statistical analysis of medium components in Relation to laccase production as per PlackettBurman design in SmF

\begin{tabular}{|c|l|c|c|c|c|c|}
\hline Factors & Medium components & effect & S.E. & $\mathbf{t ( x i )}$ & P-value & $\begin{array}{c}\text { Confidence } \\
\text { level }(\%)\end{array}$ \\
\hline X1 & Cupric sulphate & 141.1 & 34.88 & 4.04 & 0.02 & 97.27 \\
\hline X2 & Temperature & 108.43 & 34.88 & 3.1 & 0.05 & 94.7 \\
\hline X3 & Inoculum size & 93.2 & 34.88 & 2.67 & 0.07 & 92.44 \\
\hline X4 & Substrate weight & 8.86 & 34.88 & 0.25 & 0.81 & 18.41 \\
\hline X5 & Time Course & 22.63 & 34.88 & 0.64 & 0.56 & 43.73 \\
\hline X6 & Alumina & 54.84 & 34.88 & 1.57 & 0.21 & 78.6 \\
\hline X7 & Pyrogallol & 162.31 & 34.88 & 4.65 & 0.01 & 98.12 \\
\hline X8 & Yeast extract & 114.32 & 34.88 & 3.27 & 0.04 & 95.34 \\
\hline X9 & Agitation & 42.18 & 34.88 & 1.2 & 0.31 & 68.67 \\
\hline X10 & pH & 31.98 & 34.88 & 0.91 & 0.42 & 57.31 \\
\hline X11 & Dextrose & 84.48 & 34.88 & 2.42 & 0.09 & 90.59 \\
\hline X12 & Tryptone & 19.03 & 34.88 & 0.54 & 0.62 & 37.66 \\
\hline
\end{tabular}

Streptomyces chartreusis produced $23.1 \mathrm{U} / \mathrm{ml}$ of laccase in the basal medium. The Plackett-Burman experimental design used for the screening of physicochemical factors influencing laccase production along with the corresponding experimental and predicted values of response is shown in Table 1. Table 3 shows the coefficient of each variable (indicative of its effect), degree of freedom, standard error, and Prob $>F$ value. The positive or negative sign of the coefficient of a tested variable indicates whether an increase in the level of that tested variable enhanced or inhibited laccase production within the tested limits. The variables $X 1, X 2, X 3, X 7$, $X 8$ and $X 11$ had a positive effect on laccase production, while the rest had less influence. The Prob $>F$ value is used as a tool to check the significance of each variable. A Prob $>F$ lower than 0.0500 indicates that the effect of the parameter in question can be considered as significant at $95 \%$ confidence level. Therefore, the variables $X 1$, $X 7$ and $X 8$ were found to be statistically significant in affecting laccase production, whereas all the other variables were insignificant. The magnitude of the coefficient of each variable indicated the intensity of its effect on the studied response. The greater the magnitude, the higher was the significance of that variable. After performing Response Surface Methodology and getting result of Analysis of variance it would clearly updated that out of three only Cupric sulphate $\left(\mathrm{CuSO}_{4} .5 \mathrm{H}_{2} \mathrm{O}\right)$ found under good probable value in Table 3. 


\subsection{Optimization of significant variables using Box-Behnken design}

Based on the results of screening experiments by Plackett-Burman design, those variables with Prob $>\mathrm{F}$ value lower than 0.0500 were selected and further optimized using Box-Behnken design. The Box- Behnken design along with the corresponding experimental and predicted values of the laccase yield is given in Table 4 .

TABLE 4. Box-Behnken design matrix with experimental and predicted values of laccase production

\begin{tabular}{|c|c|c|c|c|c|c|c|c|}
\hline \multirow{2}{*}{$\begin{array}{c}\text { Trial } \\
\text { no. }\end{array}$} & \multicolumn{9}{|c|}{ Variables } & \multicolumn{2}{c|}{ Laccase yield } \\
\cline { 2 - 9 } & \multicolumn{2}{|c|}{ Cupric sulphate } & \multicolumn{2}{c|}{ Pyrogallol } & \multicolumn{2}{c|}{ Yeast extract } & \multicolumn{2}{c|}{ U/gm } \\
\cline { 2 - 9 } & Coded & Actual & Coded & Actual & Coded & Actual & Experimental & Predicted \\
\hline 1 & -1 & 0.05 & 0 & 0.75 & -1 & 1.50 & 38.00 & 39.24 \\
\hline 2 & 0 & 0.28 & 0 & 0.75 & 0 & 2.25 & 310.00 & 304.57 \\
\hline 3 & 0 & 0.28 & +1 & 1.00 & +1 & 3.00 & 87.22 & 92.65 \\
\hline 4 & 0 & 0.28 & -1 & 0.50 & -1 & 1.50 & 289.00 & 287.76 \\
\hline 5 & +1 & 0.50 & -1 & 0.50 & 0 & 2.25 & 38.88 & 47.28 \\
\hline 6 & 0 & 0.28 & -1 & 0.50 & +1 & 3.00 & 290.00 & 305.07 \\
\hline 7 & +1 & 0.50 & 0 & 0.75 & -1 & 1.50 & 134.00 & 118.93 \\
\hline 8 & 0 & 0.28 & 0 & 0.75 & 0 & 2.25 & 330.00 & 321.60 \\
\hline 9 & 0 & 0.28 & +1 & 1.00 & -1 & 1.50 & 26.88 & 17.24 \\
\hline 10 & 0 & 0.28 & 0 & 0.75 & 0 & 2.25 & 45.43 & 31.60 \\
\hline 11 & +1 & 0.50 & +1 & 1.00 & 0 & 2.25 & 43.55 & 57.38 \\
\hline 12 & -1 & 0.05 & +1 & 1.00 & 0 & 2.25 & 70.00 & 79.64 \\
\hline 13 & +1 & 0.50 & 0 & 0.75 & +1 & 3.00 & 128.00 & 105.20 \\
\hline 14 & -1 & 0.05 & -1 & 0.50 & 0 & 2.25 & 134.00 & 105.20 \\
\hline 15 & -1 & 0.05 & 0 & 0.75 & +1 & 3.00 & 50.00 & 105.20 \\
\hline 16 & 0 & 0.28 & 0 & 0.75 & 0 & 2.25 & 134.00 & 105.20 \\
\hline 17 & 0 & 0.28 & 0 & 0.75 & 0 & 2.25 & 80.00 & 105.20 \\
\hline
\end{tabular}

TABLE 5. Analysis of variance (ANNOVA) for the quadratic model

\begin{tabular}{|c|c|c|c|c|c|}
\hline Sum of Source & Squares & Mean df & F Square & p-value & Prob $>$ F \\
\hline Model & $1.726 \mathrm{E}+005$ & 9 & 19175.75 & 18.94 & 0.0004 \\
\hline A-Cupric Sulphate & $1.060 \mathrm{E}+005$ & 1 & $1.060 \mathrm{E}+005$ & 104.71 & $<0.0001$ \\
\hline B- Pyrogallol & 670.15 & 1 & 670.15 & 0.66 & 0.4427 \\
\hline C- Yeast Extract & 3887.86 & 1 & 3887.86 & 3.84 & 0.0909 \\
\hline $\mathrm{AB}$ & 1 & 1232.71 & 1.22 & 0.3063 & - \\
\hline $\mathrm{AC}$ & 1 & 759.55 & 0.75 & 0.4151 & - \\
\hline $\mathrm{BC}$ & 1 & 15.60 & 0.015 & 0.9047 & - \\
\hline $\mathrm{A}^{2}$ & 1 & 54532.96 & 53.87 & 0.0002 & - \\
\hline $\mathrm{B}^{2}$ & 1 & 6064.01 & 5.99 & 0.0443 & - \\
\hline $\mathrm{C}^{2}$ & 1 & 1819.02 & 1.80 & 0.2220 & - \\
\hline Residual & 7086.52 & 7 & 1012.36 & - & - \\
\hline Lack of Fit & 1225.72 & 3 & 408.57 & 0.28 & 0.8388 \\
\hline Pure Error & 5860.80 & 4 & 1465.20 & - & - \\
\hline Cor Total & $1.797 \mathrm{E}+005$ & 16 & - & - & - \\
\hline
\end{tabular}

TABLE 6. Predicted $R^{2}$ verses adjusted $R^{2}$ value

\begin{tabular}{|c|c|c|c|}
\hline Sum of Source & Value & Sum of Source & Value \\
\hline Std.Dev. & 31.28 & R-Squared & 0.9606 \\
\hline Mean & 131.12 & Adj R-Squared & 0.9098 \\
\hline C.V. \% & 24.27 & Pred R-Squared & 0.8399 \\
PRESS & 28769.06 & Adeq Precision & 12.472 \\
\hline
\end{tabular}

The data were analyzed by multiple regression analysis using the Design-Expert software and the following equation was obtained as, $\mathrm{Y}=+105.20+115.11 \mathrm{~A}+9.15 \mathrm{~B}+22.05 \mathrm{C}-17.55 \mathrm{AB}-13.78 \mathrm{AC}+1.98 \mathrm{BC}+113.80 \mathrm{~A}^{2}-$ $37.95 \mathrm{~B}^{2}-20.79 \mathrm{C}^{2}$ where $Y$ is the predicted value of laccase yield and $A, B$ and $\mathrm{C}$ are the coded values for Cupric 
sulphate, Pyrogallol and Yeast extract respectively. The experimental data were statistically analyzed by the analysis of variance (ANOVA) and the results are shown in Table 5. The ANOVA of the quadratic regression model indicated that the model was significant, as the F-value for the model was 18.94 . There was only $0.04 \%$ chance that the 'model F-value' this large could occur due to noise. The Prob>F value of the model was 0.0004 , which also confirmed that the model was highly significant. The coefficient estimate and the corresponding Prob $>F$ values (Table 5) suggested that among the independent variables studied, only Cupric sulphate had a significant effect on laccase production by Streptomyces chartreusis. The "Lack of Fit F-value" of 0.28 implies the Lack of Fit is not significant relative to the pure error. There is a $83.88 \%$ chance that a "Lack of Fit F-value" this large could occur dueto noise. Non-significant lack of fit is good. The multiple regression coefficients $\left(\mathrm{R}^{2}\right)$ had a value of 0.9606 , indicating that the model could explain up to $96.06 \%$ of the variability of the response. The value of $R^{2}(0.9606)$ indicated a good agreement between the experimental and predicted values of laccase yield (Table 6). The "Pred R-Squared" of 0.8399 is in reasonable agreement with the "Adj R-Squared" of 0.9098. Adeq Precision measures the signal to noise ratio. A ratio greater than 4 is desirable. Our ratio of 12.472 indicates an adequate signal. The effect of the interaction of various physicochemical parameters on laccass production by Streptomyces chartreusis was investigated by plotting the response surface curves against any two independent variables while keeping the third independent variable at the ' 0 ' level. Thus three response surfaces were obtained by considering all the possible combinations. The interactive roles of Cupric sulphate, Pyrogallol and Yeast extract on laccase production by Streptomyces chartreusis are illustrated in the threedimensional curves of the calculated response surface shown in Figs. 1 to 7.

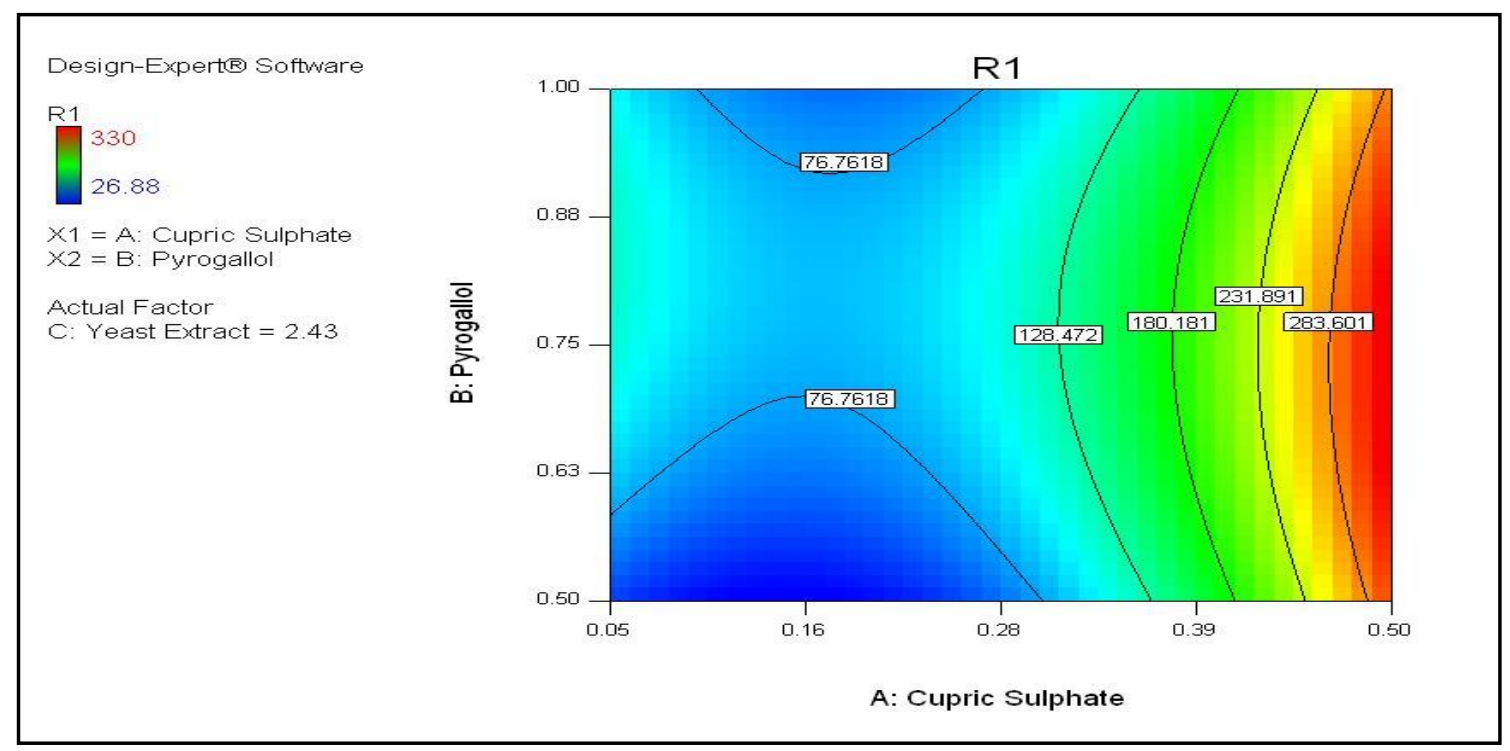

Fig. 1- Response surface curve between Cupric sulphate and Pyrogallol

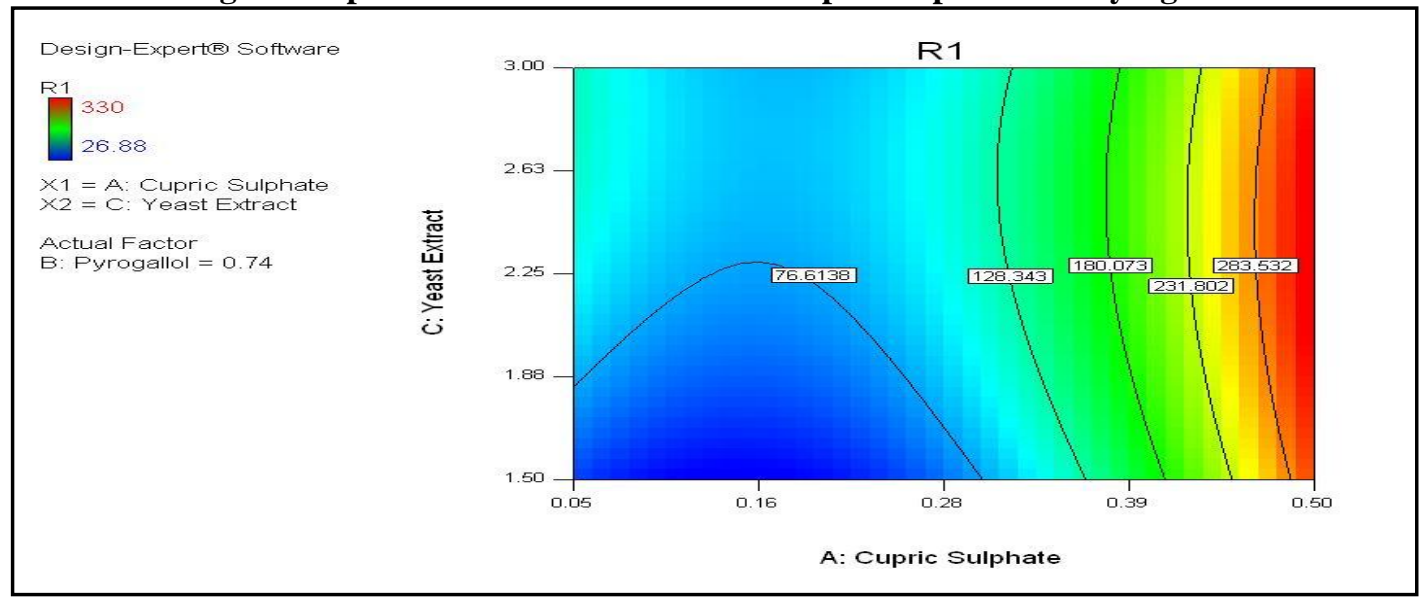

Fig 2- Response surface curve between Cupric sulphate and Yeast extract

As per figure 1, the response between Cupric sulphate and Pyrogallol produced higher laccase only when Yeast extract concentration is 2.43 gram/L. Similarly in figure. 2 the response between Cupric sulphate and Yeast extract gives higher laccase production only when Pyrogallol concentration is $0.74 \mathrm{~mL} / \mathrm{L}$. On the same way as per figure. 3, when concentration of Cupric sulphate is around 0.50 gram/L then Pyrogallol and Yeast extract 
gives highest laccase production. The 3-D plot for the same will also generated to show the effect of all three variables with suitable predicted concentrations as per figures. 4 to 6 , where R1 stands for yield of laccase.

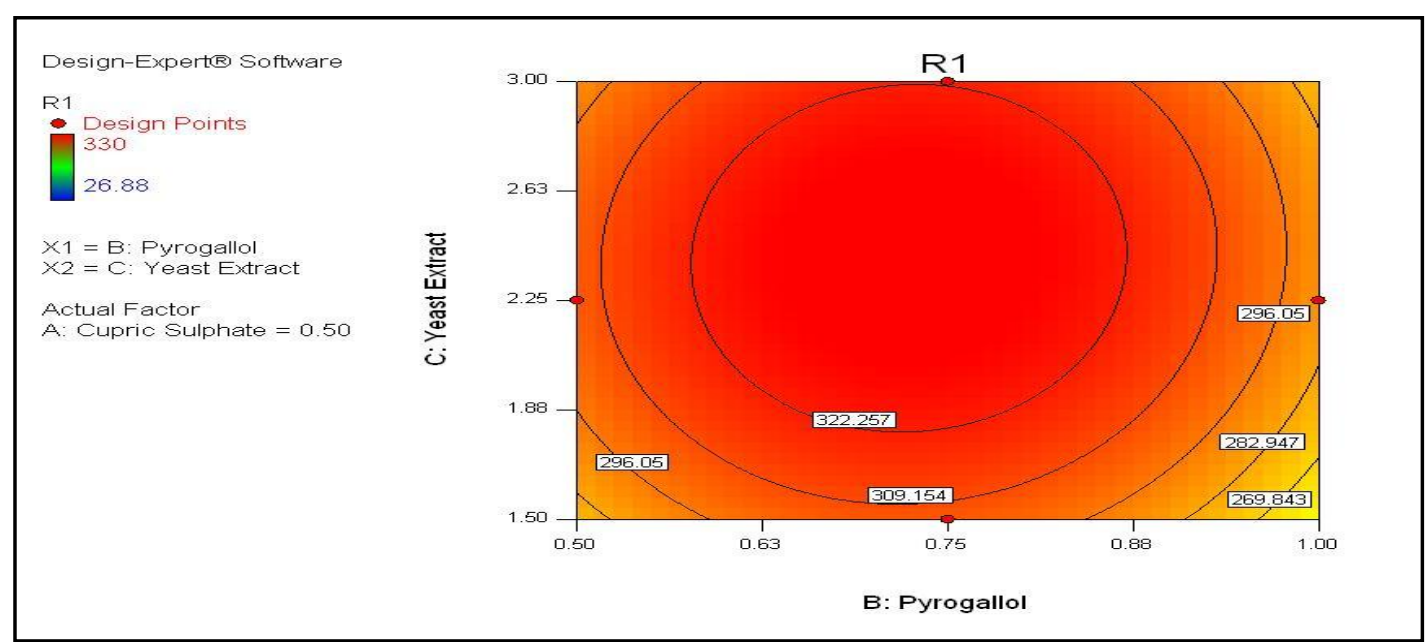

Fig. 3- Response surface curve between Pyrogallol and Yeast extract

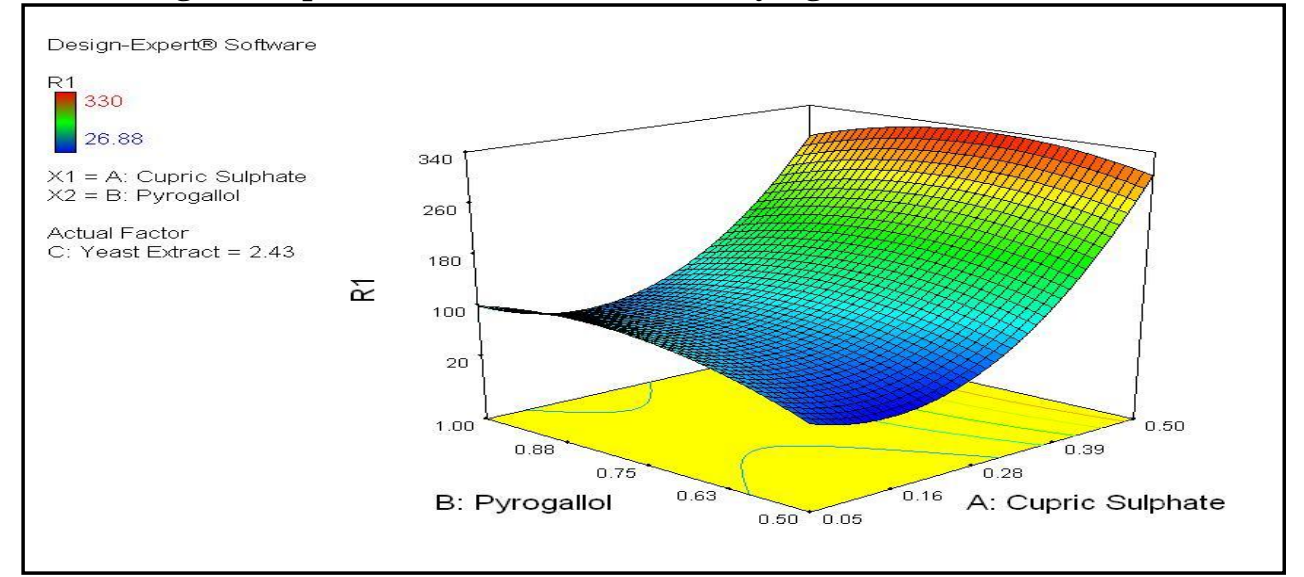

Fig. 4- 3D Surface Plot effect of Cupric sulphate and Pyrogallol at 2.43 (g/l) of Yeast extract

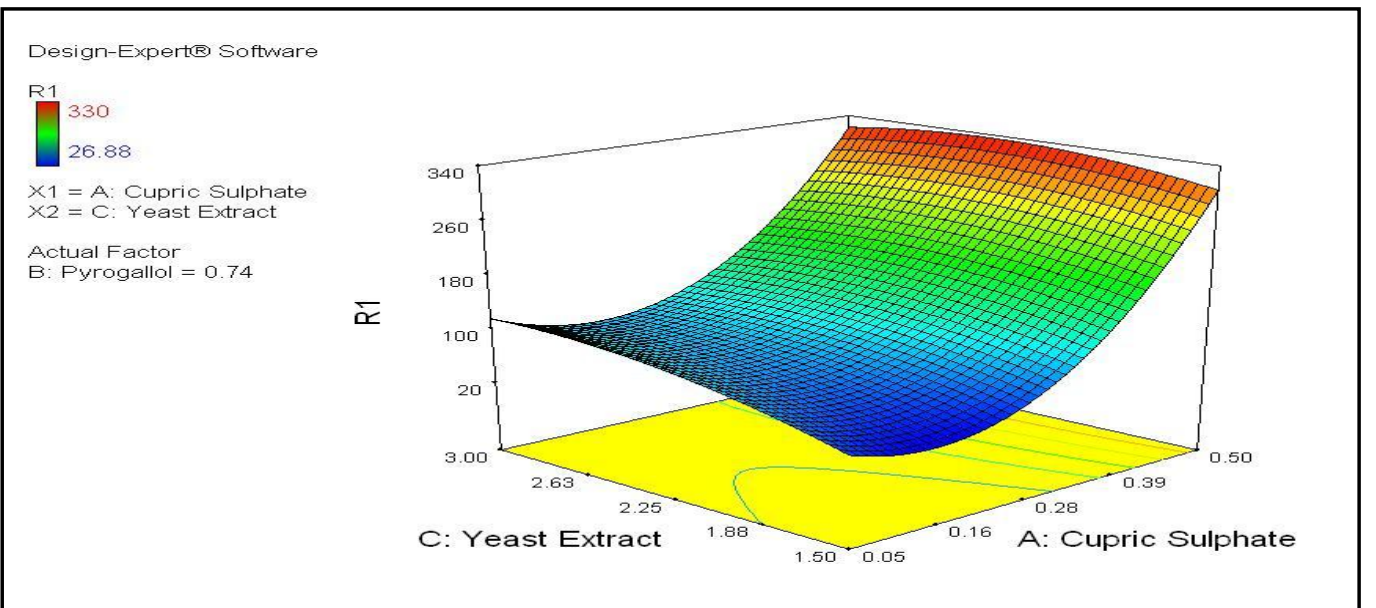

Fig. 5 - 3D Surface Plot effect of Cupric sulphate and Yeast extract at $0.74(\mathrm{ml} / \mathrm{l})$ of Pyrogallol

The standard plot of graph between predicted and actual value (Figure. 7) was also generated to show the degree of relativness towards the experimental data. 


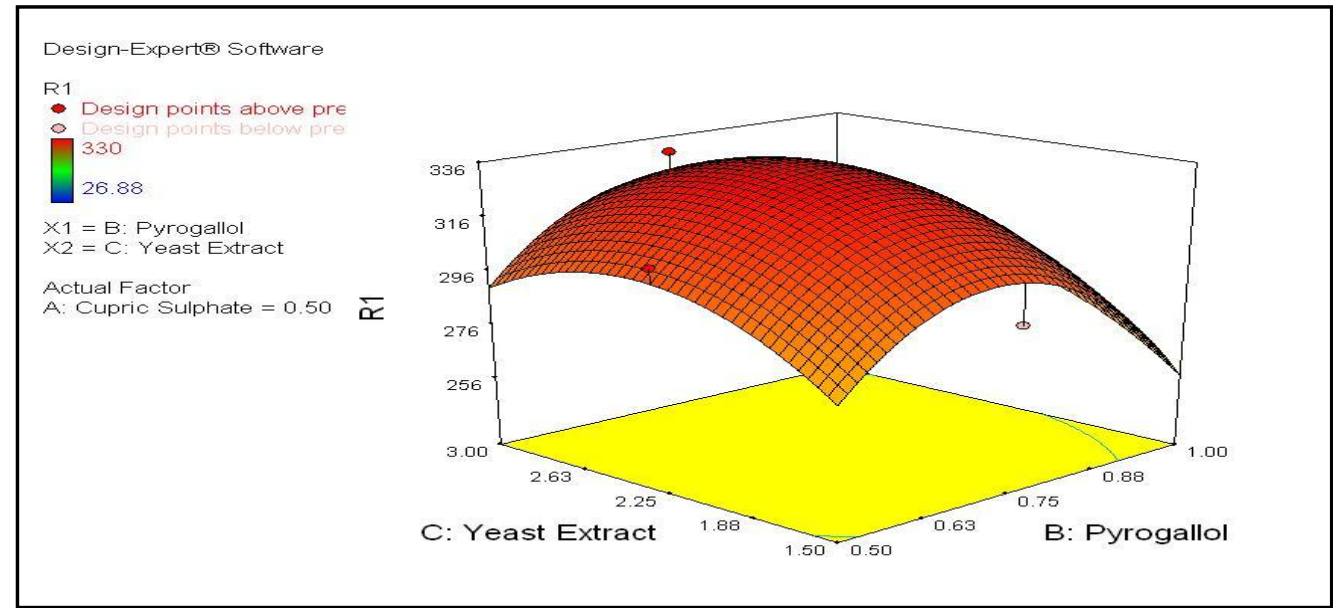

Fig. 6- 3D Surface Plot effect of Yeast extract and Pyrogallol at 0.50 (g/l) of Cupric sulphate

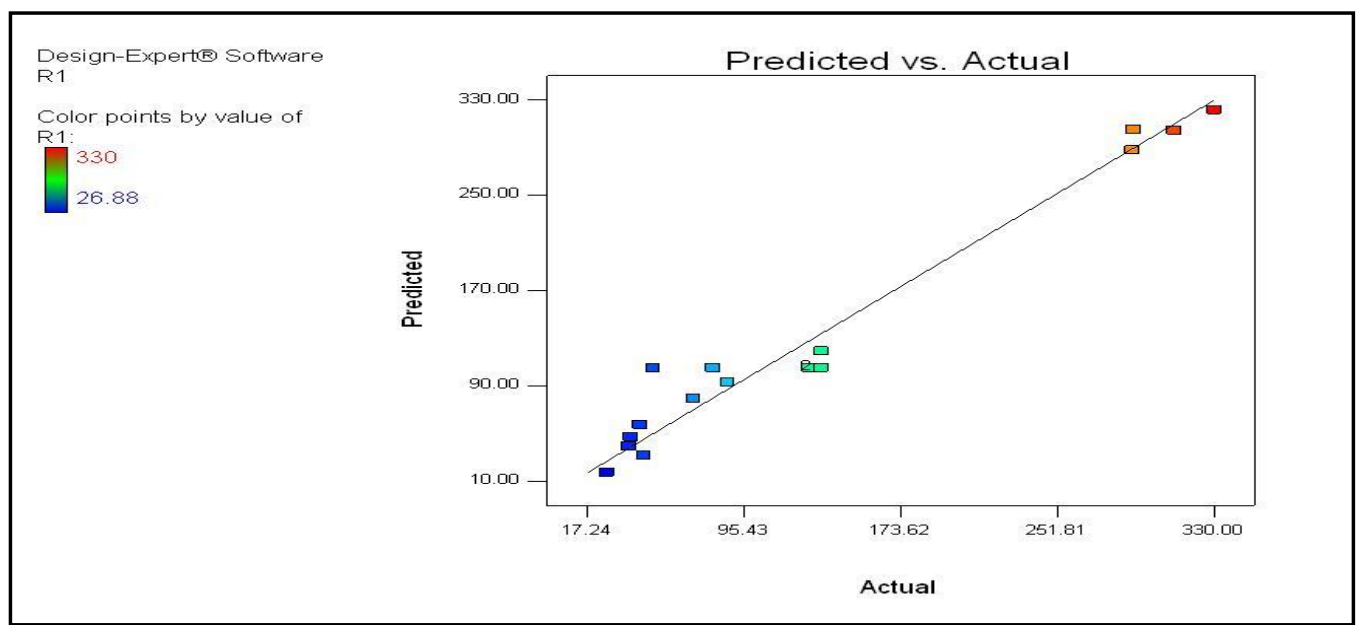

Fig. 7- Predicted with Actual value

\section{Conclusion}

In the present study, Box-Behnken design was useful in studying the physicochemical factors that supported and enhanced production of laccase by Streptomyces chartreusis under submerged fermentation. Currently, there is a lot of interest in the scientific community around the world in exploiting novel microorganisms. In this context, the results obtained during the course of this study indicate the scope for utilization of Streptomyces chartreusis strain NBRC 12753 (NCBI Accession No. JQ086575) for laccase production through submerged fermentation. In this study a statistical methodology, a combination of PlackettBurman design and Box-Behnken design, was shown to be effective and reliable in selecting the statistically significant factors and finding the optimal concentrations of those factors in $\mathrm{SmF}$ using rice bran for laccase production. Hence rice bran was found to be a good substrate for the production of laccase by filamentous bacteria under SmF. Among twelve nutrients investigated in the Plackett-Burman design Cupric sulphate, Pyrogallol and Yeast extract were selected because of their statistically significant and positive effects $(\mathrm{P}<0.05)$ on the production of laccase. There after a Box-Behnken design was employed to optimize the optimal concentrations of these three nutrients in the fermentation medium in order to maximize laccase production. A second-order model was established to identify the relationship between the three factors and laccase yield. The final concentrations $(\mathrm{g} / \mathrm{L})$ in the $\mathrm{SmF}$ medium optimized with $\mathrm{RSM}$ were $0.50 \%$ Cupric sulphate, $0.74 \%$ Pyrogallol and 2.43\% Yeast extract using rice bran as the solid substrate. Applying this optimized medium, the maximum productivity of laccase $(23.4 \mathrm{U} / \mathrm{ml})$ was achieved at $30 \circ \mathrm{C}$ after $72 \mathrm{~h}$. Incorporation of the most suitable conditions and nutrient supplements to the $\mathrm{SmF}$ medium resulted in an approximately $9 \%$ increase in enzyme yield.

\section{Acknowledements}

We would like to thank all the participants in this study, the efforts of the staff of the laboratory is also appreciated. The authors will also like to appreciate the effort of Department of Life Sciences, School of Sciences, Gujarat University in the success of this work. 


\section{Reference}

[1] RS Chhaya and HA Modi, Selective isolation and screening of laccase producing Streptomyces, Biotechnology an Indian Journal, 7(2), 2013, 71-79.

[2] RR Singhania, RK Sukumaran, AK Patel, C Larroche and A Pandey, Advancement and comparative profiles in the production technologies using solid-state and submerged fermentation for microbial cellulases, Enzyme and Microbial Technology, 46(7), 2010, 541-549.

[3] G Janusz, J Rogalski and J Szczodrak, Increased production of laccase by Cerrena unicolor in submerged liquid cultures, World Journal of Microbiology and Biotechnology, 23(10), 2007, 1459-1464.

[4] A Demir, P Aytar, S Gedikli, A Çabuk and M Arisoy, Laccase Production with Submerged and Solid State Fermentation: Benefit and Cost Analysis, Journal of Biology and Chemistry, 39(3),2011, 305-313.

[5] G Songulashvili, V Elisashvili, SP Wasser, E Nevo and Y Hadar, Basidiomycetes laccase and manganese peroxidase activity in submerged fermentation of food industry wastes, Enzyme and Microbial Technology, 41(1-2),2007, 57-61.

[6] M Téllez-Téllez, JF Fernández, AM Montiel-González, C Sánchez and G Díaz-Godínez, Growth and laccase production by Pleurotus ostreatus in submerged and solid-state fermentation, Applied Microbiology and Biotechnology, 81(4),2008, 675-679.

[7] S Bakkiyaraj, R Aravindan, S Arrivukkarasan and T Viruthagiri, Enhanced Laccase Production By Trametes hirusta Using Wheat Bran Under Submerged Fermentation, International Journal of ChemTech Research, 5(3),2013, 1224-1238.

[8] K Rajendran, MSM Annuar and MAA Karim, Optimization of nutrient levels for laccase fermentation using statistical techniques, Asia-Pacific Journal of Molecular Biology and Biotechnology, 19(2), 2011,73-81.

[9] ND Davis and WT Blevins, Methods for laboratory fermentation, In Microbial Technology,2 (Ed.), 1979,Academic Press. London.

[10] BA Auld, Mass production of fungi for biopesticides, Plant Protection Quarterly, 8(1), 1993, 7-9.

[11] BA Auld and L Morin, Constraints in the development of bioherbicides, Weed Technology, 9(3), 1995, 638-652.

[12] LJ Stowell, Submerged fermentation of biological herbicides. In Microbial control of weeds, (Ed.), D.O. Chapman and Hall, New York,1991, 225-261.

[13] RL Plackett and JP Burman, The design of optimum multifactorial experiments, Biometrika, 33(4), 1946, 305-325.

[14] KN Niladevi and P Prema, Effect of inducers and process parameters on laccase production by Streptomyces psammoticus and its application in dye decolorization, Bioresource technology, 99(11), 2008, 4583-4589.

[15] GS Anisha, RK Sukumaran and P Parukuttyamma, Statistical optimization of $\alpha$-galactosidase production in submerged fermentation by Streptomyces griseoloalbus using response surface methodology, Food Technology and Biotechnology, 46(3), 2008, 171-177.

[16] U Chhaya and A Gupta, Optimization of media components for laccase production by litter dwelling fungal isolate Fusarium incarnatum LD-3, Journal of basic microbiology, 50(1), 2010, 43-51.

[17] GEP Box and DW Behnken, Three level design for the study of quantitative variables. Technometrics, 2, $1960,455-475$. 